First Peoples Child \& Family Review

An Interdisciplinary Journal Honouring the Voices, Perspectives, and Knowledges of

First Peoples through Research, Critical Analyses, Stories, Standpoints and Media

Reviews

\title{
Strategies to Revive Traditional Decision-Making in the Context of Child Protection in Northern British Columbia
}

\section{Tara Ney, Carla Bortoletto and Maureen Maloney}

Volume 7, Number 2, 2013

URI: https://id.erudit.org/iderudit/1068841ar

DOI: https://doi.org/10.7202/1068841ar

See table of contents

Publisher(s)

First Nations Child and Family Caring Society of Canada

\section{ISSN}

1708-489X (print)

2293-6610 (digital)

Explore this journal

Cite this article

Ney, T., Bortoletto, C. \& Maloney, M. (2013). Strategies to Revive Traditional Decision-Making in the Context of Child Protection in Northern British Columbia. First Peoples Child \& Family Review, 7(2), 60-72.

https://doi.org/10.7202/1068841ar
Article abstract

For indigenous peoples, recovering from colonial rule and aspiring to flourish, the revival of traditional decision making (TDM) is considered essential. However, transitioning from established colonial practices to TDMs is not well understood. In this paper we identify some of the challenges experienced by a First Nation urban community in the north east of British Columbia as they have tried to develop and implement a culturally-relevant child and family-centered traditional decision-making (TDM) process in the context of government-regulated child protection system. Specifically, we problematize a collaborative decision-making strategy-Family Group Conferencing (FGC). FGCs are premised on values of collaboration, participation, and empowerment, and because this strategy shares many of the values and aspirations of Traditional Decision-Making (TDM), there is a temptation to directly download and incorporate FGCs into the TDM model. In this paper we explore five challenges that warrant particular attention in developing TDM model in this contemporary context: 1) power, 2) cultural adaptability, 3) family support and prevention, 4) coordinator "neutrality", and 5) sustainable support. We conclude with eight recommendations to overcome these challenges while developing TDMs in a child protection context.
This document is protected by copyright law. Use of the services of Érudit (including reproduction) is subject to its terms and conditions, which can be viewed online.

https://apropos.erudit.org/en/users/policy-on-use/ 


\title{
First Peoples Child \& Family Review
}

An Interdisciplinary Journal Honoring the Voices, Perspectives and Knowledges of First Peoples through Research, Critical Analyses, Stories, Standpoints and Media Reviews

\section{Strategies to Revive Traditional Decision-Making in the Context of Child Protection in Northern British Columbia}

\author{
Tara Ney ${ }^{\mathrm{a}}$, Carla Bortoletto ${ }^{\mathrm{b}}$ and Maureen Maloneyc \\ a PhD, R. Psych., Assistant Professor, School of Public Administration, University of Victoria, BC, Canada \\ ${ }^{\mathrm{b}}$ BSc, MPA, Director, Child and Family Initiatives, BC Association of Aboriginal Friendship Centres, Victoria, BC, Canada

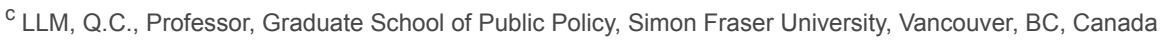

Dr. Ney holds a BA (Hons) and Ph.D. in Psychology from Southampton University, and an M.A in Dispute Resolution from the University of Victoria. Prior to her faculty appointment at the School of Public Administration, Tara worked in government, non-profit, and private sectors as a clinical and forensic psychologist, and has extensive experience in community development, both locally (restorative justice programming) and internationally (post-conflict zones). Her current research focuses on exploring more inclusive but effective ways to do our policy arguments. She is the author of over 40 journal articles and reports, as well as two edited volumes. In 2008 she was elected to political office as a municipal counselor in Oak Bay.

Carla Bortoletto holds a BSc and a Masters Degree in Public Administration from the University of Victoria. She has worked in the government, private and non-profit sectors in policy, research, and program development. Currently, Carla is the Director of Child and Family Initiatives with the BC Association of Aboriginal Friendship Centres where she works to bring culture and self-determination into Aboriginal healing \& support processes.

Maureen Maloney Q.C. is Professor of Public Policy at Simon Fraser University. Previously she was the Lam Chair in Law and Public Policy and Director of the Institute for Dispute Resolution at the University of Victoria. She returned to the University of Victoria following a term as Deputy Minister to the Attorney General (1993 to 2000) and Deputy Attorney General (1997 to 2000) of the Province of British Columbia. Before assuming these positions, Prof. Maloney was the first woman to be a Dean of Law in British Columbia. She has published and lectured extensively. Her current teaching and research interests relate conflict management/resolution particularly in marginalized populations (especially Indigenous).

\begin{abstract}
For indigenous peoples, recovering from colonial rule and aspiring to flourish, the revival of traditional decision making (TDM) is considered essential. However, transitioning from established colonial practices to TDMs is not well understood. In this paper we identify some of the challenges experienced by a First Nation urban community in the north east of British Columbia as they have tried to develop and implement a culturally-relevant child and family-centered traditional decision-making (TDM) process in the context of government-regulated child protection system. Specifically, we problematize a collaborative decision-making strategy-Family Group Conferencing (FGC). FGCs are premised on values of collaboration, participation, and empowerment, and because this strategy shares many of the values and aspirations of Traditional Decision-Making (TDM), there is a temptation to directly download and incorporate FGCs into the TDM model. In this paper we explore five challenges that warrant particular attention in developing TDM model in this contemporary context: 1) power, 2) cultural adaptability, 3) family support and prevention, 4) coordinator "neutrality", and 5) sustainable support. We conclude with eight recommendations to overcome these challenges while developing TDMs in a child protection context.
\end{abstract}

Corresponding author:

Tara Ney, University of Victoria, PO Box 1700, STN CSC, Victoria, BC, V8W 2Y2

\subsection{Introduction}

As Indigenous communities continue to exercise their right for self-determination, taking 
First Peoples Child \& Family Review, Volume 7, Number 2, 2013

Acknowledgement: We would like to acknowledge the Elders, as well as the First Nation, Aboriginal, and Metis families in the northeast of British Columbia who welcomed us on their land and shared their stories. Thanks also to the Neenan staff for their support, and the British Columbia Law Foundation for funding this research.

ownership of both statutory and child welfare agencies becomes a primary mandate to ensure the safety and well-being of their people. Much of this work involves engaging communities to develop and embrace traditional decision-making (TDM) processes and systems that will foster increased collaboration and involvement of families. The importance of reviving TDM cannot be underestimated. For example, Tuso (2011) shows that if these indigenous systems of conflict resolution do not occupy a major space in their cultural landscape, then the essential social and psychological infrastructure that supports these cultures to flourish, also disappears, resulting in utter chaos and cultural demise. He concludes that "negligence of indigenous processes of conflict resolution. . . has had negative consequences for peoples of traditional societies, [who] have experienced considerable levels of group humiliation, ambivalence toward their own cultures, division, and disorientation" (p.266).

The significance of reviving TDM processes notwithstanding, strategies for transitioning from established colonial practices to TDMs is not well understood. In this paper we draw on our experience working with Nenan, a First Nations support and advocacy agency. Their mandate is to support First Nation (Slavey, Cree, Dane zaa), Aboriginal and Métis families in the north east of British Columbia to develop and implement a culturally-relevant child and family-centered TDM process. Transition from the status quo child protection system to reinstitution of TDM processes is regarded as a key strategy to address the overrepresentation of Aboriginal children in care.

As part of this community development process, Nenan decided there is value in first understanding the merits and challenges of Family Group Conferencing (FGC) processes. FGC is a collaborative decision-making process that has been administered by the Ministry of Child and Family Development in the north east of BC since 2001. FGC is informed by traditional practices from many cultures and aims to recognize both individual and collective rights. In many respects, the values and goals of FGC align with those of TDM. The FGC process values family participation, collaboration, and empowerment in decision-making; respects the need and capacity of families and kinship to care for their children; and affirms the culture of the family group. However, even though FGC processes share many of the same values and goals of TDM processes, the promise of FGC-to more fully engage families and community in making important and better decisions that affect their lives-is not always realized. For example, anecdotal evidence from families and advocates tell us that family participants may not have been involved in pre-conference and/or follow-up plans, they frequently do not feel heard or empowered in the conferences, and their legal rights have on occasion been usurped without the safeguards of the legal system (see Ney, Stoltz, \& Maloney, 2011). Of particular concern is that Aboriginal children continue to be overrepresented in care in this region.

Thus, as urban communities transition from conventional to TDM models of care, there may be a temptation to download FGCs to develop TDM systems, again because of the ostensible alignment of values and goals (e.g. MacDonald, Glode, \& Wien, 2005). Though there may be some merit to this strategy, this paper will reveal there are also considerable challenges, that 
if left unheeded, may contribute to perpetuation of oppressive practices in child welfare. The purpose of this paper is to identify practices that will best support the development of TDM processes where the delivery of FGCs already exist. To do this we will: 1) review the best practices identified in FGC literature; 2) explore some of the challenges related to the implementation of FGCs in the Indigenous child protection context; and, 3) make recommendations that will inform effective development and implementation of TDM processes.

\subsection{Methodology}

To complete this paper we conducted a literature review of FGC best practices and Indigenous decision-making in child welfare cases. We used EBSCO Host, CRKN Wiley Online library, and Google Scholar search engines as our research tools. Combinations of key phrases included: Family Group Conference (FGC), Family Group Decision Making (FGDM), best practices, literature review, collaborative practice/planning, collective decision-making, child welfare/protection, Indigenous/Aboriginal family decision-making, Indigenous/Aboriginal child welfare/protection, and Indigenous/Aboriginal FGC/FGDM. The review resulted in articles from edited books, peerreviewed articles, as well as grey literature and official reports published by government and nonprofit organizations. These key articles are listed in the reference section of this paper.

From these selected papers we identified and explored specific issues related to FGC best practice literature. A second scan (using the same search engines as above) was then conducted to deepen our understanding of these specific best practice issues. Here we used the following phrases to conduct the search: "the land" and child welfare, Indigenous/Aboriginal alternative dispute resolution, culture and child welfare, traditional decision-making, empowering practice and child welfare, empowering families, power and decision-making, wraparound, key decision points, child protection/welfare, and disproportionality child welfare decisions. These papers were then critically examined for themes that addressed the challenges with implementing FGC.

\subsection{Findings}

Approximately half of the twenty-five articles identified address best practice issues with regard to family group conferencing (FGC) and/or family group decision-making (FGDM). ${ }^{1}$ The remaining articles provide more depth and exploration on the identified challenges of implementing FGCs. In the next section, we present findings that include: 1) a summary of the issues identified in the FGC best practice literature; and 2) the challenges of implementing FGCs in an Indigenous context.

\subsection{Summary of Best Practices Literature}

The best practices FGC literature cited in the references addresses practice issues related to FGC protocol (AHA, 2010; Barnsdale \& Walker, 2007; CHS, 2008; Connolly \& McKenzie, 1999; Crampton, 2004; Helland, 2005; MCFD, 2005; Merkel-Holguin, 2004; Rohm \& Bruce, 2008; Sherry, 2008). The most common practice issues focus on: preparation, coordinator role, meaningful extended family involvement, private family time, managing power and family dynamics, and ensuring good follow-up practices. The details of how to conduct good practice in the delivery of FGC is not the focus of this paper, but can be read in the papers cited. Of

1 In the literature, FGDM is used as an umbrella term for FGC and other methods of family decision-making that have evolved across various jurisdictions. 
First Peoples Child \& Family Review, Volume 7, Number 2, 2013

importance here is that there is a body of work that demonstrates consensus of the best practice issues and how to deliver FGC to meet its intended goals. Overall, we found that the mainstream literature is consistent in their conclusion that FGC is a useful tool for family inclusion in child protection decision-making processes.

Amongst the articles reviewed is a 2010 report published by the American Humane Association (AHA) entitled, "Guidelines for Family Group Decision Making in Child Welfare" ("Guidelines"). The AHA Guidelines were developed during two years of consultation and deliberation with 20 family group decision-making practitioners and policy makers from across North America. The primary objective of these consultations was to produce a document that gives child welfare agencies confidence to do their work based on the most "current state of knowledge and reservoirs of wisdom relating to the practice of FGDM" (AHA, 2010, p.7).

The AHA Guidelines is a practical resource in this regard: the contents acknowledge many of the issues highlighted in the research we reviewed and are intended to both raise awareness about, as well as provide practical guidance for case management. For these reasons, the AHA Guidelines stand apart from the other documents reviewed, in that they were developed using a participatory conceptual framework (Prilleltensky, Rossiter, \& Walsh-Bowers, 1996) to engage diverse stakeholder groups. The AHA Guidelines, in our review, is the most comprehensive compilation of FGC best practices to date, as it provides practical guidance on roles and responsibilities of family participants, supports, community members, and professionals. In particular, and throughout the AHA Guidelines, the role of the coordinator is described in great detail. Best practice guidance is also provided on various phases of the family meeting (meeting preparation, family meeting delivery, and follow-up), as well as referral practices, systemic support, training, and administration. The AHA Guidelines is a current and substantive resource that can inform development and implementation of TDM. We recommend:

THAT the AHA Guidelines be used as one tool to inform the development of a TDM model.

\subsection{Challenges}

In the previous section we detailed that the review of FGC literature, and the AHA Guidelines in particular, reveal a plethora of useful best practices to deliver FGC in the context of mainstream child and family services. Building from this body of work, we have identified specific challenges that are especially pertinent to Indigenous cultures that may be in the process of transitioning from the conventional to a traditional decision-making system. These challenges include: 1) power; 2) cultural adaptability; 3) family support and prevention; 4) coordinator "neutrality"; and 5) sustainable support. The remainder of this paper addresses these challenges and provides recommendations to assist Indigenous cultures in their work to develop a TDM.

\subsubsection{Power}

The research we have reviewed identifies the issue of power as important. For example, Sherry (2008) described how participants of FGC expressed their troubling experiences around power imbalances. She observes that participants "talked about the power differential ... and stressed the importance of personal awareness and acknowledging this differential" (p. 31). Connolly and McKenzie (1999) concur and caution that "a sure way of undermining effective participatory practice is to neglect the significance of power dynamics within and across systems" (p. 83). The AHA Guidelines (2010) also addresses these power concerns and warns that " $[w]$ ithout agencies' 
determined efforts to avoid such imbalances, racial and ethnic minority families and families that are poor or socially disadvantaged are at high risk of disproportionate agency responses to their situations" (p.6). Similarly, Healy \& Darlington (2009) point to the challenges of negotiating the tensions between the conventional child protection system and the FGC principles of family empowerment, participation, and collaborative decision-making. They conclude that reconciling how power is played out may be "one of the most complex and sensitive aspects of social work practice" (p.420). And finally, attempting to understand this complexity, in a recent study, Ney, Stoltz, \& Maloney (2011) show how (invisible) power-that exists in the dominant institutional and structural forces-can exert itself to override the ability of an FGC intervention to be inclusive, collaborative, and empowering and thus negatively shape the experience of families and children. Specifically, this research confirms previous research (e.g., Healy and Darlington, 2009) that the FGC process is vulnerable to co-optation by powerful child protection institutions and systems, and that participants find it problematic (Sherry, 2008). Importantly, this research also illustrates that professionals - even those fully aligned with the values of FGC-are not always aware of the way power imbalances may undermine the FGC goals (Ney et al., 2011).

For these reasons, we urge that any family support program take the issue of power seriously and include practical strategies for addressing power imbalances. Previous best practice work has advised that practitioners and programmers make a "determined effort" (AHA, 2010, p.6) to address power imbalances: in our view, this is the right objective but an inadequate strategy to address the problem of power. Our review of the literature, as well as observations of the experience of workers and participants, leads us to conclude that there is an absence of practical strategies in the research, best practice guidelines, and training to effectively overcome power imbalances. We conclude that practical strategies that intentionally address power issues are required. The work of Boud (2010) and Fook (2010) offer insights and practical strategies in critical reflexivity to assist practitioners to take seriously context, culture, ideology, and discursive power. To address the issue of power we recommend:

THAT all professionals who work in the child protection system, and the delivery of FGCs in particular, have training in "critical reflexivity" which includes:

- training in awareness of the history of social work with First Nations People ${ }^{2}$

- understanding accountability to the history of harm that is perpetuated

- exposing and becoming aware of one's role in perpetuating the oppression (Cowie, 2010) ${ }^{3}$

- providing experiential orientation around local Indigenous culture (Bortoletto, 2011)

\subsubsection{Cultural Adaptation}

The literature we reviewed is clear that direct downloading of mainstream FGC or mediation strategies into Indigenous cultures is not the right approach (Blackstock \& Trocme, 2005). Cameron (2006) explains how alternative dispute resolution mechanisms, such as FGC and mediation, while potentially compatible with Indigenous values, are nevertheless "imports from other areas of the world" (p.18). Employment of these "cookie-cutter" approaches obstructs the possibility of eliciting culturally embedded decision-making approaches that will more effectively engage and support Indigenous communities (Helland, 2005; Merkel-Holguin, 2004).

2 PHSA's Indigenous Cultural Competency on-line training is an effective tool to achieve this objective (http://www. culturalcompetency.ca/health-authorities/provincial-health-services).

3 See Fook (2010) for ways to instigate and sustain reflective practices within front-line workers. 
First Peoples Child \& Family Review, Volume 7, Number 2, 2013

Cameron reminds us that Aboriginal communities "since time immemorial, have had, and still do have, principles and processes in place to deal with disharmony in the community" (Lee as cited in Cameron, 2006, p.3). It is essential that grassroots processes be used to elicit local values, customs, and practices of TDM (Avruch \& Black, 1991; Cameron, 2006; Connolly \& McKenzie, 1999; Walker, 2004).

The value of a bottom-up approach in this regard has long been understood in the conflict resolution field. For example, John Paul Lederach (1997), a renowned practitioner and researcher on developing culturally appropriate decision-making tools, proposes an "elicitive" (as opposed to prescriptive) strategy that respects local understandings and meanings of events and interactions as they play out in specific contexts. In these instances "implicit Indigenous knowledge ... is a valued resource for creating and sustaining appropriate models of conflict resolution" (p.56). More practically, Avruch \& Black (1991) recommend a process called "ethnopraxis" which involves the use of culture-specific mapping to show how local Indigenous communities traditionally address disharmony. Similarly, Cameron (2006), in her review of Indigenous decision-making models, supports the use of mapping processes that are conducted before program implementation. And, finally, in a compilation of 11 Indigenous TDM programs in British Columbia, Harder (2009) shows how extensive consultation with local Indigenous community members is fundamental to designing effective community-specific processes.

This kind of local consultation and bottom-up development points to the need for meaningful attention to "deep culture" or worldview when processing conflict (Goldberg, 2009). Tuso (2011) reviews cases where communities who have experienced cultural devastation and violent conflicts in response to colonial practices, have turned to "indigenous processes of peacemaking in the hope of finding more appropriate mechanisms of healing and reconciliation" (p.265), and reviews cases where reconciliation and healing have resulted from these efforts. But these are not add-on strategies, and coordinators who attempt to down-load hybridized strategies run the risk of perpetuating colonial policies and practices (Blackstock \& Trocme, 2005). Furthermore, as LeBaron (2003) reminds us, "cultural fluency" is an essential capacity that requires the ability to acculturate in any number of contexts. Developing "cultural fluency" is not achieved by following check-lists of dos and don'ts. Our concern is that the value of cultural sensitivity is underplayed in the AHA Guidelines. ${ }^{4}$

It is not the intention of this discussion to impose another non-Indigenous model or recommendation on Aboriginal families. But differences in worldview between various First Nations' groups, as well as between First Nations, Métis, and urban Aboriginal people within BC must be understood and taken seriously. Walker (2004) suggests that legitimatizing worldviews is critical to creating a sustainable and supportive space for Indigenous families and insists that "[t]o act otherwise is to marginalize people's abilities to function within their worldviews, an act of ontological violence" (p.530). For this reason, we recommend:

THAT TDM processes include culture-specific mapping to identify traditional Indigenous decision-making practices and to co-create the model with Indigenous communities;

4 Section III.24. (in the AHA Guidelines) devotes a half page (of a 60-page document) to "Cultural Considerations" and advises that the coordinator "show respect" and demonstrate "a genuine interest in the family's culture and an understanding of how the family's culture has been historically treated by the dominant culture" (p. 39). But with no recognition on how "power" can easily co-opt efforts to be culturally sensitive (Goldberg, 2009), nor acknowledgment of "deep culture" (Lederach, 1997), and the need to develop "cultural fluency" (LeBaron, 2003), the guidance is inadequate in ensuring that coordinators conduct a culturally sensitive decisionmaking process.

(C) Tara Ney, Carla Bortoletto, and Maureen Maloney 
Strategies to Revive Traditional Decision-Making in the Context of Child Welfare Protection

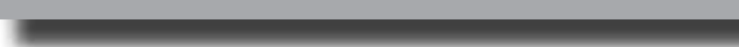

THAT Indigenous children and families are engaged in the design, development, implementation and monitoring of the TDM;

THAT families choose the TDM that suits their specific circumstances; and

THAT Elders are involved to ensure that cultural protocols are followed, and to solidify the grounding of decisions in community relationships; and

THAT Coordinators are trained in cultural fluency.

\subsubsection{Family Support and Prevention}

The literature on decision-making in child welfare systems shows that from the moment a child protection report is made, there are several decision points before the decision is made to apprehend a child. Each of these decision points may direct a family closer to preventative supports or closer to apprehension depending on the time, resources, family situation, and the persons making the decisions (Bortoletto, 2011). Moreover, typically, in conventional systems, the evidence demonstrates that the likelihood of apprehension at each decision point is disproportionately greater for Indigenous peoples than non-Indigenous (Derezotes et al., 2008). Most best practice recommendations for FGCs are confined to safety and care plans-which are conducted after a child has been apprehended. It is a matter of considerable concern that there is inadequate involvement of families earlier in the decision-making process-a strategy that would contribute to mitigation of disproportionate apprehensions (Tilbury, 2009).

The reasons that family involvement does not occur earlier are numerous. Sherry (2008) points out that the "question of timing ties into who holds the power to offer family group conferencing, determine the time, or decide whether or not a referral is appropriate (p.33). Furthermore, the literature shows that when the process of family decision-making is not mandated, social workers with differing worldviews can determine a family outcome without first involving families in the decisions that affect their lives (Crampton, 2004). Such inadvertent oversight provides further support for our previous recommendation that professionals who work in and with the child protection system have training in "critical reflexivity".

Literature that addresses this issue urges organizations to incorporate families and family groups into the decision-making process early on and throughout the process-not just as a one-time, end-of-the-road event or technique (Sherry, 2008; Centre for Human Services, 2008; Walker, 2004). Indeed, this requires reconceptualization of the FGC as a process, not an event (Maloney \& Ney, 2008). Sherry (2008) recommends the use of several FGC's throughout a family's involvement with child protection and furthermore to allow the family to decide when it is an appropriate time for an FGC to take place. In BC, the Interior Métis Child and Family Services Society have incorporated two different decision-making processes into their service delivery model: a smaller, shorter meeting "to address immediate planning needs", and a larger, longer meeting to develop care and safety plans (Harder, 2009, p.18). In Lakidjeka, Australia, non-statutory Indigenous case workers are expected to remain fully engaged with families and ensure their voices are heard from the time of first contact and, where necessary, throughout the child protection process (Higgins \& Butler, 2007, p.11). The Okanagan Nation Alliance ensures family participation before intake to mitigate, if not circumvent families' deeper involvement in the child protection system. In her review of the use of alternative dispute resolution models in child protection, Cameron (2006) concludes that early family involvement is common, accepted, and culturally appropriate. Together the literature confirms that early and ongoing involvement 
First Peoples Child \& Family Review, Volume 7, Number 2, 2013

of families in the care of their children will mitigate the disproportionate apprehension of Indigenous children. In our view, the AHA Guidelines do not adequately promote early and sustained involvement of families. For these reasons, we recommend:

THAT TDM strategies develop and implement processes and/or policies that will enable Indigenous families and communities to partake in child protection decisions early (at the first point of contact) and throughout the process;

THAT the use of family decision-making processes be available as a preventative measure to families who are not yet known to the child protection system but may benefit from the supportive family process; and,

THAT families be entitled to instigate the use of such processes if they determine that it would assist them at a particular time.

\subsubsection{Coordinator "Neutrality"}

Mainstream best practice generally supports the use of one coordinator who is considered "independent and impartial" (AHA, 2010; Helland, 2005; Barnsdale \& Walker, 2007). The FGC reference guide published by $\mathrm{BC}$ government's MCFD echoes this notion stating that families will be referred to an impartial "coordinator" (MCFD, 2005, p.2). However, other literature we reviewed explains that this practice "contrasts sharply with Indigenous approaches, which honor interconnections within the natural world" (Walker, 2004, p.536). In his review of Indigenous approaches to conflict, Walker (2004) found that "Indigenous choice of facilitators also reflects an emphasis on relationships... [where coordinators were] well known to the participants and . .. well versed in community beliefs, values, and history" (p.537).

The same was true of the BC models described in Harder's report (2009). In each of the 11 models that were designed and implemented by Indigenous organizations, most facilitators had some connection with the individual family, a practice that is contrary to the ethic of "dual relationship". In some instances where coordinators were not original members, the community embraced the coordinator and invited him/her to become more involved within the community, its members, and traditions. In other instances, the model intentionally recruited a co-coordinator with deeper community connections. Harder (2009) concludes that, "personal history [e.g. same band, same community] and positive relationships with the community appear to be significant indicators of successful service delivery" (p.5).

These examples point to the importance of creating a safe space in Indigenous communities to ensure that Aboriginal people both trust the person(s) coordinating the process, as well as have confidence that the coordinator has knowledge of, understands, and cares for their community and culture. The Indigenous literature reviewed here indicates that trust involves a deeper relational enmeshment than merely respect. Cameron (2006) suggests that the issue of trust and coordinator neutrality be a part of the TDM consultation and design process (p.16). The AHA Guidelines concur that families choose their coordinators (AHA, 2010) to fit within their traditional Indigenous worldview (e.g. the coordinator may be a well known and respected member of their community). Because this relational ethic deeply conflicts with mainstream literature that advocates for coordinator independence and impartiality we recommend: 
Strategies to Revive Traditional Decision-Making in the Context of Child Welfare Protection

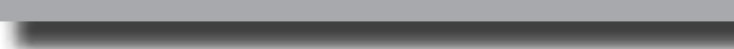

THAT TDM strategies exercise a cautious approach to the issue of neutrality and ensure the design process explicitly explores who is recruited to coordinate family involvement and decision-making.

\subsubsection{Sustainable Support}

According to the AHA Guidelines, the role of the coordinator is complete once the final copies of a plan are distributed. At this point, it is the family and social worker who are jointly responsible for ensuring progress and accountability for implementation (2010, p.58). This practice, though, has the effect of reverting the two parties (the family and the child protection agency) back into the classic child protection environment with none of the FGC checks and balances related to power or other challenges and concerns. Rather than continue to nurture the spirit of the process, the FGC process does not kick in again until something in the relationship breaks down. We've emphasized above, under "family support and prevention" that the FGC is not an event, but rather a process. Merkel-Holguin agrees and warns that " $[\mathrm{w}]$ hen practitioners view family group conferencing as a tool to be used on families and not as a process in which to engage them - they overlook the key preparation and follow-up steps that are critical to building community partnerships and increasing family involvement" (as cited in Mirsky, 2003, p.2).

Our research identifies post-meeting follow-up as one of the most critical components to the successful completion of a family plan (CHS, 2008; Helland, 2005; Wintenberger McHugh, n.d.). Here, the use of an advocate can be critical. Helland (2005) states that the "one consistent and important condition associated with successful permanency with [FGC participants is having] a strong advocate for the plan" (p.34). Bortoletto (2011) also found that third-party involvement was effective in helping the family to carry out the plan, secure appropriate resources, and ensure child protection staff did not alter the provisions of the plan without due process and in particular without consultation and engagement with the family.

Promoting better follow-up practices fits with Aboriginal values that embrace relationship, interconnectedness, and expanded notions of time. In his book titled, Research is Ceremony, Shawn Wilson (2008) indicates that when a ceremony begins, the relationships that are created in that process continue to be respected. To create a safe and sustainable space for Aboriginal people, a family support service must ensure that the equitable and supportive relationships created in the decision-making process continue - rather than dissolve once people leave the "event". The research literature we reviewed is crystal clear: placing exclusive responsibility for follow up solely on the family and social worker is ineffective (Bortoletto, 2011; CHS, 2008; Helland, 2005; Wintenberger McHugh, n.d.). Accordingly, family support programs need to place as much importance upon what happens after decision-making meetings as they do upon what happens before and during them. Specifically, we recommend:

THAT during the TDM model development process, strategies and policies that will ensure sustainable and continued family support are explored and implemented.

\subsection{Conclusion}

We recognize that for a number of reasons (i.e. loss of culture; separation from community, culture and family, impact of residential schools and child welfare, etc.), not all Aboriginal families utilize their traditional culture in their approaches to family decisions. We also recognize that in many instances, FGC coordinators may be culturally aware and competent, and ensure that cultural safety 
is practiced by Aboriginal and non-Aboriginal agencies when dealing with Aboriginal families. But the concern of this paper is that for many jurisdictions, such as experienced by Nenan, downloading FGCs cannot overcome the colonialist practices that have been responsible for much of the devastating conditions of Aboriginal people. Instances where these concerns persist may require more interrogation and sensitivity of the way FGCs are practiced.

It is important to highlight the significance of the recently released AHA Guidelines (2010) to this best practice literature review. Their comprehensive description of FGC principles (consistent with other best practice literature we reviewed) and practical guidelines, make this document a useful tool to inform TDM processes. The across-the-board overview contained in the AHA Guidelines afforded us the space and opportunity to focus this report and recommendations on examining, refining and expanding key issues. Accordingly, this review and the accompanying recommendations give greater prominence to central challenges and concerns that have been raised about the workings of FGCs related to power, cultural adaptability, family support and prevention, coordinator "neutrality", and sustainable and continued support. Although many of these challenges have been identified in the FGC literature, in practice they have been minimized or downplayed. Of particular concern is the lack of direction and attention in the AHA Guidelines of how to address "deep culture" and worldview. Stronger leadership in this key document could go a long ways in shaping more culturally-attuned practices.

The overall recommendation of this paper is that these issues of culture must be taken seriously during the development of TDM processes in Indigenous communities. For example, issues of power and culture speak directly to the need for a clear acknowledgment and understanding of the devastation that colonization has caused, and continues to cause, in Indigenous communities. TDM strategies which address these critical challenges will assist Indigenous communities to revitalize their values and culture, and is consistent with and supports self-determination efforts.

We present this research as a tool to inform TDM development processes in child protection.

\subsection{Summary of Recommendations}

This review of FGC best practices and examination of five critical issues, results in the following recommendations for development of traditional decisions making models in an Indigenous context:

\section{Power}

THAT the AHA Guidelines be used as one tool to inform the development of a TDM model; and,

THAT all professionals who work in the child protection system, and the delivery of FGCs in particular, have training in "critical reflexivity" which includes:

training in awareness of the history of social work with First Nations People ${ }^{5}$

understanding accountability to the history of harm that is perpetuated

5 PHSA's Indigenous Cultural Competency on-line training is an effective tool to achieve this objective (http://www. culturalcompetency.ca/health-authorities/provincial-health-services).

(C) Tara Ney, Carla Bortoletto, and Maureen Maloney 


\section{Strategies to Revive Traditional Decision-Making in the Context of Child Welfare Protection}

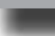

exposing and becoming aware of one's role in perpetuating the oppression (Cowie, 2010 $)^{6}$

providing experiential orientation around local Indigenous culture (Bortoletto, 2011).

\section{Cultural Adaptation}

THAT TDM processes ensure they undertake culture-specific mapping to identify traditional Indigenous decision-making practices and to co-create the model with Indigenous communities;

THAT Indigenous children and families are engaged in the design, development, implementation and monitoring of the TDM;

THAT families choose the TDM that suits their specific circumstances;

THAT Elders are involved to ensure that cultural protocols are followed, and to solidify the grounding of decisions in community relationships; and

THAT coordinators are trained in cultural fluency.

\section{Family Support and Prevention}

THAT TDM strategies develop and implement processes and/or policies that will enable Indigenous families and communities to partake in child protection decisions early (at the first point of contact) and throughout the process;

THAT the use of family decision-making processes be available as a preventative measure to families who are not yet known to the child protection system but may benefit from the supportive family process; and,

THAT families be entitled to instigate the use of such processes if they determine that it would assist them at a particular time.

\section{Coordinator "Neutrality"}

THAT TDM strategies exercise a cautious approach to the issue of neutrality and ensure the design process explicitly explores who is recruited to coordinate family involvement and decision-making.

\section{Sustainable Support}

THAT during the TDM model development process, strategies and policies that will ensure sustainable and continued family support are explored and implemented.

\section{References}

FGDM Guidelines Committee (2010). Guidelines for Family Group Decision Making in Child Welfare. Englewood, CO: American Humane Association. Retrieved April 6, 2011 from http://www.americanhumane.org/assets/pdfs/ children/fgdm/guidelines.pdf.

6 See Fook (2010) for ways to instigate and sustain reflective practices within front-line workers. 


\section{First Peoples Child \& Family Review, Volume 7, Number 2, 2013}

Avruch, K \& Black, P. (1991). The culture question and conflict resolution. Peace and Change, 16(1), 22-45.

Barnsdale, L. \& Walker, M. (2007). Examining the Use and Impact of Family Group Conferencing. Research Findings No. 26, Scottish Executive. Retrieved April 6, 2011 from http://www.frg.org.uk/pdfs/Examining\%20the\%20use\%20 and\%20impact\%20of\%20FGC.pdf

Blackstock, C. \& Trocme, N. (2005). “Community-based child welfare for Aborigianl children: Supporting resilience through structural change." In M. Ungar (Ed.) Handbook for Working with Children and Youth: Pathways to Resilience Across Cultures and Contexts (pp.357-370). Thousand Oaks, CA: Sage.

Bortoletto, C. (2006). Aboriginal Friendship Centres and child protection processes in BC. Unpublished Masters thesis. University of Victoria, Victoria: BC.

Boud, D. (2010). Relocating reflection in the context of practice. In H. Bradbury, N. Frost, S. Kilminister, and M. Zukas (Eds.), Beyond Reflective Practice: New Approaches to Professional Lifelong Learning. London: UK: Routledge (pp. 25-36).

Cameron, M. (2006). Alternate dispute resolution: Aboriginal models and practices. MCFD, Vancouver Coastal Region. Vancouver: BC.

CHS - The Centre for Human Services. (2008). Participatory Planning in Child Welfare Services Literature Review: Selected Models, Components and Research Findings. University of California, Davis: CA. Retrieved April 7, 2011 from http://academy.extensiondlc.net/file.php/1/resources/LR-ParticipatoryPlanning.pdf

Connolly, M. \& McKenzie, M. (1999). Effective participatory practice: Family group conferencing in child protection. Hawthorne, NY: Transaction Publishers.

Cowie, A. (May 2010). Anti-oppressive social work practice in child welfare: Journeys of reconciliation. Critical Social Work, 11(1), 46-51.

Crampton, D. S. (2004). Family involvement interventions in child protection: Learning from contextual integrated strategies. Journal of Sociology and Social Welfare, 31(1), 175-198.

Derezotes, D., Richardson, B., King, C.B., Kleinschmit-Rembert, J., \& Pratt, B. (2008). Evaluating multisystemic efforts to impact disproportionality through key decision points. Child Welfare, 87(2), 241-254.

Fook, J. (2010). Beyond reflective practice: reworking the 'critical' in critical reflection. In H. Bradbury, N. Frost, S. Kilminister, and M. Zukas (Eds.). Beyond Reflective Practice: New Approaches to Professional Lifelong Learning (pp. 37-51). London: UK: Routledge.

Goldberg, R. (2009). How our worldviews shape our practice. Conflict Resolution Quarterly, 26(4), 405-431.

Harder, L. (2009). Report of Aboriginal child welfare collaborative decision-making models. Vancouver, BC: Law Foundation of BC. Retrieved April 7, 2011 from http://www.lawfoundationbc.org/files/Report\%20of\%20 Collaborative\%20Decision-Making\%20Models.pdf

Healy, K.\& Darlington, Y. (2009). Service user participation in diverse child protection contexts: Principles for practice. Child \& Family Social Work, 14(4), 420-430.

Helland, J. (2005). Family group conferencing literature review: Prepared for the child and youth officer for British Columbia. Unpublished manuscript.

Higgins, J.R., \& Butler, N. (2007). Indigenous responses to child protection issues. 'Promising practices in out-of-home care for Aboriginal and Torres Strait Islander careers, children and young people' (booklet 4). Melbourne, Australia: Australian Institute of Family Studies. Retrieved April 7, 2011 from http://www.aifs.gov.au/nch/pubs/reports/ promisingpractices/booklets/booklet4.pdf

LeBaron, M. (2003). Bridging cultural conflicts: A new approach for a changing world. San Francisco, CA: John Wiley.

(C) Tara Ney, Carla Bortoletto, and Maureen Maloney 


\section{Strategies to Revive Traditional Decision-Making in the Context of Child Welfare Protection}

Lederach, J. (1997). Building peace: Sustainable reconciliation in divided societies. Washington, D.C.: U.S. Institute of Peace Press.

MacDonald, N., Glode, J. and Wien, F. (2005). Respecting Aboriginal families: Pathways to resilience in custom adoption and family group conferencing. In M. Ungar (Ed.), Handbook for Working with Children and Youth: Pathways to Resilience Across Cultures and Contexts (pp.357-370). Thousand Oaks, CA: Sage. (pp. 357-370)

Maloney, M. \& Ney, T. (2008). Bringing narrative inquiry to family group conferencing. Protecting Children, 23(4), 48-59.

Merkel-Holguin, L. (2004). Sharing Power with the people: Family Group Conferencing as a dDemocratic eExperiment Special issue, "Restorative Justice and Responsive Regulation." Journal of Sociology \& Social Welfare, 31(1), 155-173.

Ministry of Children and Family Development. (2005). Family Group Conference Reference Guide. Victoria, BC: Queens Printer. Retrieved April 6, 2011 from http://www.mcf.gov.bc.ca/child_protection/pdf/fgc_guide_internet.pdf

Ministry of Children and Family Development. (2004). British Columbia's family development response. Victoria, BC: Queens Printer. Retrieved April 6, 2011 from http://www.mcf.gov.bc.ca/child_protection/pdf/fdr_overview_ internet.pdf

Mirsky, L. (2003). Family Group Conferencing Worldwide: Part One in a Series. International Institute for Restorative Practices: EFORUM. Retrieved April 20, 2011 from http://www.iirp.org/article_detail.php?article_id=NDMz

Ney, T., Stoltz, J., Maloney, M. (2011). Voice, power, and discourse: Experiences of FGC participants in the context of child protection. Journal of Social Work, 1-19.

Prilleltensky, I., Rossiter, A., \& Walsh-Bowers, R. (1996). Preventing harm and promoting ethical discourse in the helping professions: Conceptual, research, analytical, and action frameworks. Ethics \& Behavior, 6(4), 287-306.

Rohm, A., \& Bruce, L. (2008). Responding to culture in family group decision making: Summarizing interviews with Kevin Ward and Inshirah Hassabu. Protecting Children, 23(4), 38-46.

Sherry, M. (2008). What have we learned about family group conferencing and case management practices? Protecting Children, 23(4), 20-37.

Tilbury, C. (2009). The over-representation of Indigenous children in the Australian child welfare system. International Journal of Social Welfare, 18, 57-64.

Tuso, H. (2011). Indigenous processes of conflict resolution: Neglected methods of peacemaking by the new field of conflict resolution. In: T. Matyok, J. Senehi, and S. Byrne (Eds.), Critical Issues in Peace and Conflict: Theory, Practice, and Pedagogy (pp. 245-270). Plymouth, UK: Lexington Books.

Walker, P. O. (2004). Decolonizing conflict resolution: Addressing the ontological violence of westernization. American Indian Quarterly, 28 (3\&4), 527-549.

Wilson, S. (2008). Research is ceremony: Indigenous research methods. Canada: Fernwood Publishing. 